\title{
On Construction of Circulation System of Fresh Agricultural Products under Supply Chain
}

\author{
Qiuping Ni \\ Economics and Management School, Yibin University, Yibin, 644000, China
}

Keywords: Supply chain. Fresh agricultural products. Circulation system

\begin{abstract}
There are various problems related to supply chain in circulation system of our fresh agricultural products. On the basis that problems existing supply chain management of fresh agricultural products at present have been analyzed comprehensively, this thesis proposes some strategies, such as strengthening logistic infrastructure construction, developing farmers' cooperative organization actively and perfecting information service system etc., which is of great significance for constant improvement and development of the circulation system of fresh agricultural products under the supply chain.
\end{abstract}

\section{Introduction}

In addition to grain, fresh agricultural products are one of the major sources of food nutrition in China and play an extremely important role in people's daily living consumption. Besides, sound and perfect circulation system of fresh agricultural products appears to be quite significant for us to improve people's daily living standard, ensuring food security and improve farmers' incomes. Since production mode of fresh agricultural products is limited by developmental situations of market, this causes the situation that circulation of fresh agricultural products is obstructed and related efficiency is low. As a new-type management concept, supply chain theory draws more and more attention from all social circles and its practice tends to be deepened continuously. However, theoretical researches and practical application are quite weak for current fresh agricultural products in China at present. Thus, supply chain theory should be applied to circulation of fresh agricultural products to drive our rural economy to realize sustainable development actively.

\section{Practical problems in circulation of fresh agricultural products under supply chain}

\section{Too long supply chain causes high loss ratio easily}

At present, circulation system of fresh agricultural products in China mainly transfers from producers of agricultural products to wholesalers at producing areas, circulates to wholesale market in selling places and then flows to consumers by retail ends like supermarket, restaurants and farmers' market. Thus, it is obvious that fresh agricultural products usually can be delivered to consumers after four times' transportation and sale. According to observation on circulation of fresh agricultural products' supply chain, it is found that fresh agricultural products of China usually encounter problems, such as the supply chain is too long and there are too many links. As a result, the following problems are usually caused. First of all, loss ratio is increased. In accordance with related statistics, the loss ratio of fresh agricultural products belonging to fruits and vegetables in each circulation link reaches up to $25 \%$, while the loss ratio in western developed countries is often less than $5 \%$. In consideration of the situation that there are too many links in the supply chain, price is added at every level, which leads to the result that fresh agricultural products' price is rather high. In accordance with statistics, logistics cost of fresh agricultural products in China accounts for over 60\% of total cost, while that in western developed countries is only about $10 \%$. One important reason why consumers, especially urban citizens, complain about high price is that fresh agricultural products' price keeps high all the time. Finally, too long supply chain causes nutrition loss for such products and even triggers quality problems. 


\section{High logistics loss in the process of circulation lead to high circulation cost easily}

Because functions of circulation facilities are not complete and processing procedures, such as fresh-keeping, storage, process, transportation and sorting, are not lacked for fresh agricultural products when such products are circulated, too high circulation cost is caused by too high loss in the process of circulation. Compared with western developed countries, the loss ratio of fresh agricultural products in China in circulating links like picking, transportation and storage is rather high, which causes constant increase in logistics cost in the circulation system of fresh agricultural products and then raises circulation cost of fresh agricultural products.

Uneven benefit distribution in each link leads to missing benefit affiliating mechanism easily

Since fresh agricultural products of China are featured by small production and large market, it causes the situation that producers of fresh agricultural products stay in a state of scattered operation. As a result, the scene of homogeneous competition is formed and all participants have significant difference in amount of information and control power they hold under supply chain management. Lacking information and corresponding circulating approaches, farmers stay at an unfavorable position, which causes uneven benefit distribution and brings a series of problems. First of all, common farmers stay at the top of supply chain, own rather weak ability to negotiate price of fresh agricultural products and have to expand production scale constantly to obtain more benefits. Secondly, common farmers undertake nearly all corresponding risks of supply chain. When farmers do marketing by relying on friends or familiar channels, the phenomenon of chaos and even dull sale is usually caused. Next, from a macroscopic perspective, farmers usually expect agricultural products and change production scale and structure practically according to market price of fresh agricultural products in the last production cycle. Thus, price of some fresh agricultural products have huge periodic fluctuation. Finally, the supply chain of fresh agricultural products, which adopts the mode 'enterprises + cooperative organizations + bases + farmers', is a benefit affiliating system that is not sound enough. Once market price exceeds order price, farmers usually break contracts and sell agricultural products to purchasing enterprises offering a higher price. On the contrary, enterprises may reduce purchase practically in many forms, for instance, improving quality standards for agricultural products. All of these have negative impacts on the supply chain of fresh agricultural products.

\section{Too many circulation links tend to improve difficulty in traceability of product quality easily}

The circulation mode of fresh agricultural products, which takes wholesale mode and peddlers' market as major approaches in traditional sense, usually encounters the scene that there are too many links in the process of their circulation and subjects of circulation are rather chaotic. This improves difficulty in traceability of agricultural products, so it is difficult to ensure quality security of fresh agricultural products. Because of practical situations of fresh agricultural products' circulation and advantages of supply chain management in China, it is quite necessary to use more advanced supply chain theory to reform the traditional circulation system of fresh agricultural products in our country. Its important significance is reflected by the following aspects. Firstly, integrated supply chain management is realized, so it can ensure that corresponding information can be delivered accurately and timely in each circulation link to reduce all common blindness in farmers' production process and decrease their operational risks practically. Secondly, central enterprises of supply chain management usually hold sound logistics facilities of agricultural products and advanced logistics management techniques, so it is possible to ensure freshness of fresh agricultural products and reduce loss of agricultural products in the process of circulation feasibly. Thirdly, primary fresh agricultural products often have low price, it is quite essential to use integrated operation of supply chain to realize the purpose, i.e., appreciation. In doing so, all interest subjects in the supply chain can obtain appreciation in the aspect of value.

\section{Strategies about construction of the circulation system of fresh agricultural products under the supply chain}




\section{Developing organizational forms of the supply chain of fresh agricultural products constantly}

Essence of supply chain management mode lies in the fact that companies are based on mutual coordination and complementary advantages in order to build overall competitive strength of the supply chain. In a realistic level, one of the important reasons why the supply chain of fresh agricultural products in China does not have powerful competitive force is that degree of systematism is too low. Especially, under the construction condition of three-level circulation system of agricultural products in China at present, the supply chain in the whole process of fresh agricultural products from production to marketing is rather long. Thus, operating cost is high and efficiency is low. Consequently, it is essential to strengthen and perfect organizational forms of the supply chain of fresh agricultural products, use modern enterprise system to establish fresh agricultural products' circulation system with systematism of chain operation and then cultivate operating mode of supply chain organizations whose subjects are agricultural product companies in order to realize integration of the producing and marketing process of fresh agricultural products practically and construct fresh agricultural products' supply chain with international competitive force.

\section{Working hard to shorten the supply chain to strengthen binding system of the supply chain of fresh agricultural products}

In accordance with problems, such as the supply chain of fresh agricultural products in China is too long and there are too many intermediate links, it is essential to integrate resources feasibly and optimize structure of the current supply chain. Meanwhile, we should work hard to deal with the phenomenon, i.e., 'three kinds of chaos' on roads, and ensure green channels can be unobstructed. Additionally, we should realize real combination between agricultural production bases and catering companies practically, solve problems existing in circulation of fresh agricultural products effectively and reduce loss of products feasibly by applying new methods to circulation of fresh agricultural products, such as connection between farm and store, connection between farmer and supermarket and connection between farmer and restaurant. Furthermore, interest binding system of fresh agricultural products, which is sounder and more perfect, should be formed in order to guide related interest subjects of the supply chain to form interest linkage in the form of contracts actively. All subjects should follow laws and regulations practically and keep stability that interest linkage has. Moreover, construction about sharing system of the supply chain's profit appreciation should be enhanced largely and methods (for example, policy support) are used to show enterprises' sense of social responsibility in order to guide all subjects to help weak subjects in various forms like profit return and regurgitation-feeding and form common value and interest relationship.

\section{Developing farmers' organizations actively to improve organizational degree}

In order to ensure supply of fresh agricultural products can have stability and persistence and reduce risks of transactions with single farmers and transaction cost effectively, enterprises operating fresh agricultural products may tend to do transactions with farmers' cooperative organizations. At the same time, on the basis of mutual cooperation among farmers, a kind of powerful and effective force can be formed, unfavorable position that single farmers hold in the process in which they carry out negotiation and deal with all kinds of market disputes in marker of agricultural products can be changed feasibly, and cost from entrance of a single farmer to implementation of transactions in market can be reduced effectively. Thus, to build a balanced and stable supply chain of fresh agricultural products, it is essential to devote to developing farmers' cooperative organizations in order to improve organizational degree of farmers and build feasible distribution mechanism of appreciation interest.

\section{Strengthening circulation of agricultural products and infrastructure construction of cold-chain logistics}

To keep efficient operation of fresh agricultural products, we must have support of various kinds of infrastructure like wholesale market of agricultural products, warehousing facilities and transportation facilities etc. Thus, we should construct a large batch of fresh agricultural products' wholesale markets with reasonable layout and complete functions in large and medium-sized cities and main producing areas in China, increase strength about construction of logistics facilities like 
storage, processing, transportation and distribution of fresh agricultural products in our country, develop circulation organizations like chain supermarket and direct-selling distribution energetically, actively encourage cold-chain logistics enterprises to enhance strength about construction of logistics facilities like fresh-keeping, cold storage and transportation practically, improve construction of temperature-control facilities in processing of fresh agricultural products energetically, build pre-cooling facilities for affordable agricultural products reasonably, give priority to equip energy-saving and environmental cold-chain transport vehicles and devote to popularizing full-course temperature-control equipment.

Establishing and perfecting just and reasonable interest distribution system for fresh agricultural products

The supply chain management of all supermarkets and enterprises operating agricultural products, whose subjects are wholesale market, should center on fair interest distribution system. Fair and reasonable interest distribution system is an important link relating to whether the supply chain of fresh agricultural products can be successful or not. All internal nodes of the supply chain should establish a mutual trust relationship, which becomes more and more important. Fair, just and reasonable interest distribution system is a basis on which enterprises operating agricultural products can establish mutual trust. Thus, it is essential to consider interests of all participating subjects in the supply chain comprehensively and fully and enable all internal members of the supply chain to achieve the same goal and work hard to improve overall interest of the supply chain of fresh agricultural products by reasonable interest distribution.

Forming perfect information service system of fresh agricultural products

To form perfect information service system of fresh agricultural products, demands of consumers of agricultural products, node enterprises in the supply chain and intermediary organizations in market of agricultural products for information must be regarded as a premise, circulation of agricultural products should be treated as a starting point, resource integration ought to be implemented by focusing on links like production, processing, circulation and marketing of fresh agricultural products, and the most advanced computer technique can be used to excavate more information resources and develop more information about appreciation of agricultural products. In addition, information sharing system should be constructed in accordance with principles of interest sharing and risk sharing in order to satisfy demands of node enterprises in the supply chain of fresh agricultural products for information. False information and advertising in the field of fresh agricultural products must be struck by standard system construction and punishment on false publicity and false advertising that raiding the market should be enhanced feasibly in order to improve quality of information service related to agricultural products effectively.

\section{Improving standardization level of supply chain management technique related to fresh} agricultural products

One of the factors affecting supply chain management of fresh agricultural products is technical standard of such products, such as standard packaging, fresh-keeping, merchants' traceability and information management technique etc. Up to now, the foregoing techniques have not been widely popularized and applied to the supply chain of fresh agricultural products in China. Thus, when the supply chain of fresh agricultural products develops towards integration and systematization nowadays, it is essential to establish more scientific and more reasonable coordinating system in order to promote technology standardization in the supply chain of fresh agricultural products. This is critical for improvement in circulating efficiency of the supply chain of fresh agricultural products.

Improving macro management of the government for fresh agricultural products actively

The government should make feasible market management principles in order to ensure the market can operate effectively. Then, openness and fairness of transactions can be realized and both parties involved in a transaction can be protected feasibly. Besides, the government should enhance law enforcement in the field of agricultural products and fight against all kinds of unfair competition and behaviors raiding the market. At the same time, the government may consult the form in western developed countries, i.e., subsidy may be issued for agricultural products, and include some fresh agricultural products in insurance coverage in order to improve competition of our fresh agricultural 
products in market. Besides, the government ought to perfect logistics training system of fresh agricultural products to satisfy demands of the industry for logistics talent.

\section{Acknowledgments}

This thesis is a common project of Education Department of Sichuan Province (project No.: 12SB359), soft science of Science and Technology Bureau of Yibin City (project No.: 2012RY013) and a college-level task of Yibin University (project No.: 2011Q19).

\section{References}

[1] Fang Xin: Analysis of current situations and development direction of supply chain of fresh agricultural products, Agricultural Product Market Weekly (monograph about remote transactions), 2005(15).

[2] Liu Yingdong, Huang Zuhui and Wu Kexiang: Analysis of target and behaviors about supermarkets' operation about agricultural products, Commercial Age (theoretical edition), 2005(29).

[3] Liu Zhaoyun, Sun Shimin and Wang Jiyong: Progress and trend of researches on supply chain management of agricultural products in China, Business Studies, 2009(3).

[4] Zhang Xuezhi and Chen Gongyu: Selection of operation mode of agricultural product supply chain in China, China Circulation Economy, 2009(10).

[5] Liu Puhe: On circulation channels of fruit and vegetable agricultural products in China, Business Economy and Management, 2010(11). 